\title{
A biogeografia no ensino: um olhar sobre o Jardim Botânico Rodriguez Alves em Belém-Pa
}

\author{
Anderson Coelho Borges ${ }^{(a)}$, Ananda do Socorro Oeiras Paixão ${ }^{(b)}$,Gabriel Nabor \\ Figueiredo $^{(\mathrm{c})}$,Vanessa Sidrim da Silva de Souza ${ }^{(\mathrm{d})}$ \\ ${ }^{(a)}$ Faculdade de Geografia/Universidade da Amazônia, andersonborges51@ yahoo.com.br \\ ${ }^{\text {(b) }}$ Faculdade de Geografia/Universidade da Amazônia, ananda-_oeiras@hotmail..com \\ ${ }^{\text {(c) }}$ Faculdade de Geografia/Universidade da Amazônia, gabrielnabor2012@ gmail.com \\ (d) Faculdade de Geoprocessamento/Universidade Federal do Pará, vansidrim@ gmail.com
}

\section{EIXO:BIOGEOGRAFIA, MANEJO DE ÁREAS NATURAIS E PROTEGIDAS: CONSERVAÇÃO DA BIODIVERSIDADE}

\begin{abstract}
Resumo:
A biogeografia é uma ciência que possibilita a compreensão acerca das espécies da flora e fauna que detém o espaço geográfico, acrescentando também a sua importância no que se refere ao ambiente escolar, especificamente ao ensino. Dessa maneira, a verticalização que a urbanização vem causando em Belém-Pa e a ausência do conhecimento em relação a importância que ela apresenta, o presente artigo visa expor atividades biogeográficas que foram aplicadas em sala de aula e no campo de estudo: o Jardim Botânico Rodrigues Alves com o objetivo, conscientizar os alunos sobre a importância da preservação da flora e fauna da região amazônica. As atividades foram efeituadas através de levantamentos bibliográficos, ida a campo além de recursos didáticos pedagógicos. O presente trabalho é fruto do subprojeto de "Um olhar Biogeográfico dos Parques Ambientais da Grande BelémPA" surgido através do Programa de Iniciação a Docência (PIBID) vinculada a Universidade da Amazônia.
\end{abstract}

Palavras chave:Biogeografia; Atividades; Parques Ambientais.

\section{Introdução}

A abordagem sobre a tem da biogeografia é pouco aplicada na sala de aula do ensino básico através de procedimentos metodológicos diferentes dos tradicionais aplicados. Ela faz parte da ciência geográfica onde busca entender a relação entre a natureza e sociedade. Atuando de forma a compreender a distribuição geográfica dos seres vivos no espaço, como conceitua (DANSEREAU, 1949) é "a ciência que estuda a distribuição, a adaptação, a expansão e associação das plantas e dos animais (ou seres vivos)". O estudo dela para o geografo, segundo Camargo \& Troppmair:

(...) um trabalho biogeográfico do ponto de vista do 'geógrafo', tem necessidade de explicar a distribuição dos seres vivos (fauna e flora) no espaço, e correlacioná-las sempre com os demais aspectos ambientais (fatores abióticos) e o próprio Homem (fatores culturais), apresentando, assim, uma visão muito mais ampla e complexa (CAMARGO \& TROPPMAIR, p. 135, 2002).

Iniciaremos nossos estudos biogeográficos através da análise dos conceitos que envolvam a disciplina, tentando contextualizar essas informações à prática pedagógica em sala de aula através do Programa Institucional de Bolsa de Iniciação à Docência PIBID. Assim utilizamos através de métodos e técnicas 
específicas compreender os processos e leis naturais que determinam a dinâmica das paisagens, como também o uso racional do espaço e dos recursos naturais, tendo como objeto de estudo a biodiversidade amazônica presente no JBA, neste sentido, visamos mostrar a importância da biogeografia no processo de aprendizagem da geografia física.

O presente trabalho é o desdobramento da pesquisa do subprojeto de Geografia e Biologia "Um olhar biogeográfico dos Parques Ambientais da Grande Belém", desenvolvido no âmbito do Programa Institucional de Bolsa de Iniciação á Docência - PIBID/UNAMA realizada junto á Escola Estadual de Ensino Fundamental e Médio Santana Marques.

Buscamos relatar as atividades biogeográficas adotadas em sala de aula e em idas ao campo através do PIBID consistindo em uma abordagem biológica e geográfica, tendo em vista que o subprojeto é interdisciplinar com o intuito de conscientizar os alunos acerca da importância da preservação da fauna e flora da região amazônica assim como a manutenção dos recursos naturais que ela possui, utilizando desses recursos didáticos metodológicos que auxiliem no processo de ensino-aprendizagem como, por exemplo: projetos de pesquisa e extensão, dramatização, produtos cartográficos, música, feiras, trabalho em grupo e o debate, que são considerados estratégicos no ensino e como formas de avaliação, que tem a finalidade de promover a aprendizagem (SELBACH, 2010).

Assim a Biogeografia para o geógrafo deve ser entendida e aplicada. Por ela ser pouco abordada no ensino básico, requer uma busca de métodos a serem abordados nas escolas, pautadas pelo PCN's que propõe um trabalho pedagógico que visa à ampliação das capacidades dos alunos do ensino fundamental de observar, conhecer, explicar, comparar e representar as características do lugar em que vivem e de diferentes paisagens e espaços geográficos (PCN's, 1998, p15).

Desta maneira, iniciaremos nossos estudos biogeográficos através da análise dos conceitos que envolvem a disciplina, tentando contextualizar essas informações à prática pedagógica em sala de aula, de forma que os estudos possam ser desenvolvidos de maneira prática e agradável, acreditando que desse modo, os alunos poderão compreender e sistematizar o conhecimento biogeográfico, no que se refere à fauna e sua distribuição geográfica.

\section{Metodologia}

Foram feitas duas aulas que antecederam à visita a aula prática, para o reconhecimento biogeográfico "in loco". Além de anotações, registros fotográficos referentes ao nosso campo de estudo, exemplificando as espécies disponíveis no Bosque. Após isso foi montado um questionário de aula expositiva acerca dos assuntos mencionados na visita, também foram ministradas aulas expositivas relacionando a teoria biogeográfica de Troppmair com a prática, dessa forma fazendo um paralelo com a disciplina. 

OS DESAFIOS DA GEOGRAFIA FÍSICA NA FRONTEIRA DO CONHECIMENTO Instituto de Geociências - Unicamp
Campinas - SP
28 de Junho à 02 de Julho de 2017

Os estudos e as atividades realizadas tiveram como foco central o Jardim Botânico da Amazônia JBA conhecido como Bosque Rodrigues Alves que está localizado no bairro do Marco (figura 01), às margens da Avenida Almirante Barroso, umas das principais vias urbanas de circulação da cidade de Belém. O bosque foi escolhido por ser de fácil acesso pelos alunos, além de possui mais de $80 \%$ de espécies vegetais e por abrigar 435 animais de 29 espécies que vivem em cativeiro e também 29 em liberdade ou semiliberdade que estão dispersas na área de mata. As atividades foram realizadas com os alunos do $7^{\circ}$ ano do ensino Fundamental da Escola Estadual de Ensino Fundamental e Média Santana Marques, Localizado no Bairro do Panorama na cidade de Belém do Pará.

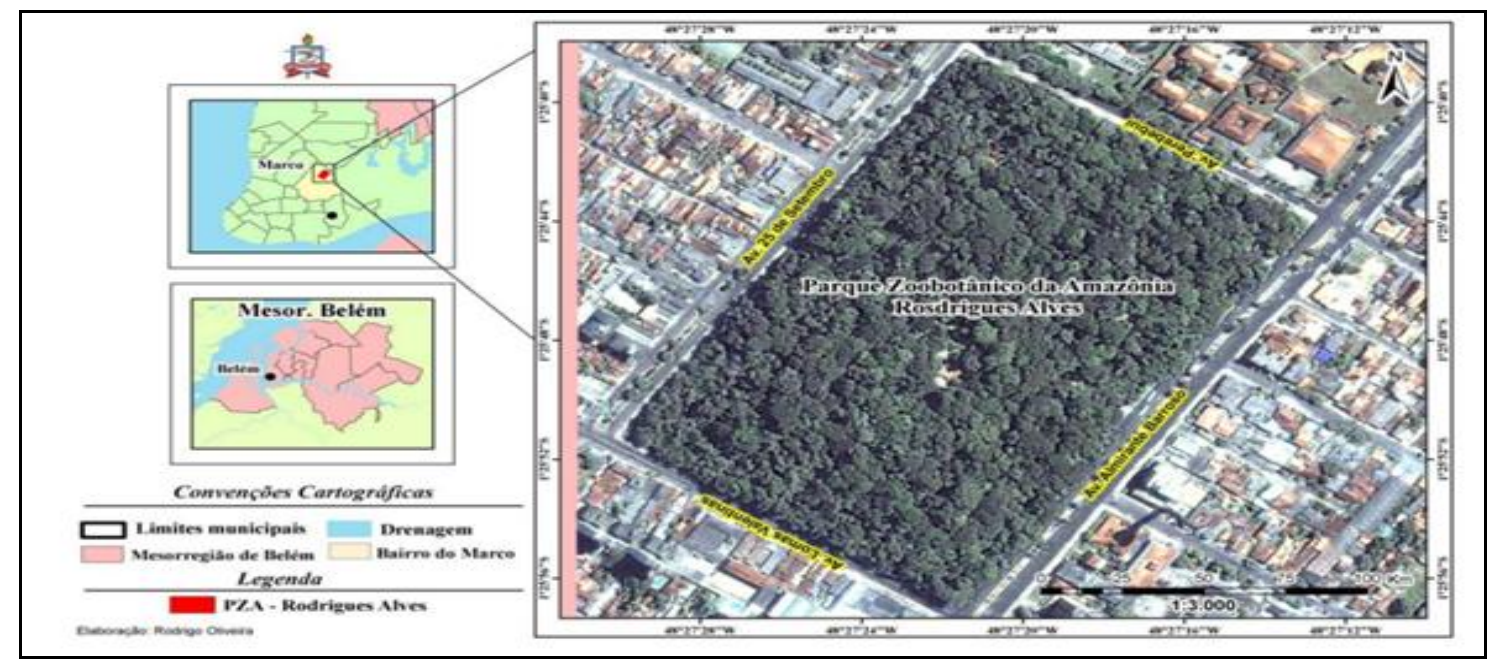

Figura 1 - Mapa de localização do Jardim Botânico da Amazônia. Fonte: (DA LUZ, p.174, 2002).

\section{Resultados e discussões}

\subsection{Atividades em sala de aula: A biogeografia (origens dos animais vertebrados do bosque Rodrigues Alves em Belém-Pá)}

A matéria, em geral, não costuma exigir os pré-requisitos que seriam necessários para uma "compreensão total" desta área do saber. Em vez disso, são exigidos pré-requisitos de uma típica "formação básica" em Geografia, Ecologia, Zoologia e Botânica, desta forma, deveriam ser apresentadas como disciplinas do currículo mínimo em Geografia, a fim de favorecer um mais eficiente aproveitamento na disciplina. Ademais, os conceitos básicos, deveriam ser mais bem destrinchados por outras disciplinas, anteriores à Biogeografia, no intuito de proporcionar de fato uma compreensão da área de conhecimento.Para que se compreenda a biogeografia é necessário entender a importância da distribuição geográfica dos seres vivos na terra. Assim o Bosque Rodrigues Alves veio a contribuir com a atividade, tendo em vista que ele abriga uma diversidade de espécies de animais de origem amazônica, ajudando, portanto na manutenção da fauna no planeta. 
O professor/supervisor de Geografia de acordo com seu conteúdo programático do ano ministrou uma aula sobre a distribuição geográfica dos seres vivos no planeta e o professor/ supervisor de Biologia deu uma aula sobre os animais vertebrados da região amazônica. Após esse momento os Bolsistas do PIBID mediante o subprojeto elaboraram uma atividade onde os alunos foram divididos em grupos e para cada um foi dado um tipo de espécie (Aves, Mamíferos, Répteis e Anfíbios). Com o auxilio dos supervisores de Geografia e Biologia, os alunos do $7^{\circ}$ ano do ensino fundamental fizeram uma pesquisa bibliográfica sobre as espécies de animais que existem no Bosque Rodrigues Alves. Além da pesquisa, os alunos preencheram uma ficha na qual continha o: nome popular da espécie, nome cientifico, família, ordem, classe, origem geográfica, ambiente e curiosidades que encontraram. A partir desse momento os grupos construíram um mapa da região amazônica, onde deveria está contida através de símbolos criados no mapa pelos alunos as espécies encontradas no Bosque e que tinham a origem geográfica nessa região. Mediante a isso, os alunos expuseram a pesquisa realizada, falando detalhadamente de cada animal pesquisado e mostrando no mapa criado por eles onde se dava a origem geográfica de cada uma das espécies.

\subsection{Visita de campo ao Bosque Rodrigues Alves em Belém-Pá.}

Em um segundo momento após a atividade realizada em sala de aula, os alunos foram levados ao Bosque Rodrigues Alves para compreenderem melhor a fauna, a flora e principalmente o histórico desse monumento, assim como sua importância no meio urbano para a cidade e população de Belém. A visita a campo foi realizada tendo o acompanhamento dos bolsistas do subprojeto de biologia e geografia, assim como os supervisores e com a ajuda de funcionários do bosque.

Os alunos entraram pelo lado esquerdo do bosque onde foram recebidos pelo historiador que relatou um pouco sobre a criação do lugar pelo então presidente da câmara municipal de Belém João Diogo Clemente Malcher em 1883, ressaltando a ideia que o espaço foi construído em virtude da necessidade de se ter espaços de lazer para a população, tendo em vista que Belém passava por um momento financeiro muito proveitoso através da exploração do Látex. (HISTÓRICO DO BOSQUE, 2005). Assim o historiador foi descrevendo as reformas pelo qual o espaço passou e a importância de sua permanência até os dias de hoje no lado urbano da cidade de Belém. Onde o Bosque garante tranquilidade e conforto em meio à correria que as grandes cidades possuem.

Depois desse momento da relevância do espaço e histórico do bosque, os alunos foram conhecer com ajuda da engenheira ambiental a flora que existe na área, como as medicinais e árvores ameaçadas em extinção. Onde ela relatou sobre as arvores centenárias que o bosque possui como a Quariquara que permanece no espaço acerca de aproximadamente 400 anos, assim como a Maçaranduba que tem 150 anos no local e a seringueira, espécie de fundamental importância para a economia da região amazônica no período de 1879 a 1912. 
OS DESAFIOS DA GEOGRAFIA FÍSICA NA FRONTEIRA DO CONHECIMENTO

Instituto de Geociências - Unicamp

Campinas - SP

28 de Junho à 02 de Julho de 2017

\subsection{Análises da fauna}

O Bosque Rodrigues Alves possui animais que viveram em cativeiros e foram levados para lá em condição de liberdade e semiliberdade, uns em condições de reabilitação, pois eles foram encontrados em condições de extremos maus tratos pelo homem. Além de possuírem animais ameaçados de extinção como a Arara azul grande, que foi muito assediada pelos alunos na visita. O peixe boi da Amazônia também participou do processo de aprendizagem dos alunos em detrimento de ser a espécie de animal mais conhecida da região amazônica através das lendas e por atualmente está classificado em ameaça de extinção pela fácil vulnerabilidade em que ele se encontra na natureza. As fotos a seguir mostram a vivencia dos alunos em uma atividade de campo no Bosque, aonde veio contribuir com o conhecimento deles através de atividades realizadas em sala de aula.



Figura 2 - Exposição sobre os animais ameaçados de extinção. Fonte: trabalho de campo 2016

\section{Considerações finais}

A Biogeografia proporcionou para os alunos o entendimento acerca das características da fauna e da flora que o bosque detém. Além de compreenderem a importância que o Bosque Rodrigues Alves desempenha da cidade de Belém. Os alunos ainda puderam compreender os aspectos climáticos de diferentes pontos da área urbana da cidade, onde a ausência e presença de vegetação arbórea acabam por influenciar no clima da área.

Diante das atividades realizadas tendo o Bosque Rodrigues Alves como área de estudo, foi possível compreender em sua plenitude o espaço geográfico através da Biogeografia, desde o conhecimento da distribuição e origem de cada espécie, além da intervenção do homem na natureza, fomentando os impactos que isso acaba gerando nela. Atentando para uma sensibilização e conscientização ambiental por parte do aluno. 


\section{Bibliografia}

BOSQUE RODRIGUES ALVES JARDIM BOTÂNICO DA AMAZÔNIA. Histórico do Bosque Rodrigues Alves. Adaptação de Biblioteca Bosque Rodrigues Alves. Belém, 2005.

CAMARGO, J. C. G.; TROPPMAIR, H. A evolução da biogeografia no âmbito da ciência geográfica no Brasil. Geografia, v. 27, n. 3, p. 133-156, 2002.

DANSEREAU, P. “Os planos da Biogeografia”. Revista Brasileira de Geografia, ano VIII, n.2, abril-junho, 1946.

NACIONAIS, Parâmetros Curriculares. Secretaria de Educação Fundamental. Brasília: MEC/SEF, v. 1998, p. 156.

SELBACH, S. História e didática. Petrópolis, RJ: Vozes, 2010. Disponível em: $<$ http://www.ipea.gov.br/desafios/index.php?option $=$ com_content\&id=2154:catid=28\&Itemid=23>. Acesso em: 20 Ago 2015. 